\title{
Adaptive Leadership Approach With COVID 19 Adaptive Challenges
}

\author{
Robert Cote \\ University of Missouri - Saint Louis
}

This paper will assess and evaluate the context of the COVID-19 Pandemic's impact on corporation, small businesses, economy, and unemployment. Also, the impact on organizations including customers, workforce, supply chain, economic outlook, and industries. Due to COVID-19, organizations are faced with risks and a complexity of challenges, including globalizations, intense competition, sustainability, speed and responsiveness to environmental changes, and the digital revolution. Adaptive leadership will be evaluated, explored, and for addressing the complexity of challenges in organizations, including: 1. What is adaptive leadership? 2. Explain the differences between technical and adaptive challenges, 3. What are the six behaviors used by adaptive leaders? They require leaders to get on the balcony "big picture", identify the adaptive challenge/technical challenge, regulate distress, maintain disciplined attention, give the work back to the employees, and protect voices from below. The conclusion with summarize the findings of adaptive leadership, challenges, and application with post COVID-19 pandemic work environment.

Keywords: adaptive leadership, adaptive challenges, technical challenges, COVID-19, leadership behaviors, adaptive work environment

\section{INTRODUCTION}

COVID-19 Pandemic has resulted in organizations to close their doors, file for bankruptcy, lay off employees, and operate their business with the challenges that are impacting their business livelihood and customers. Organizations will need to mobilize employees, stabilize operations/finances, and get people back to work. To better understand the challenges presented by the pandemic, organizations will need to conduct a review of data collected and gain insights from the pandemic. What are the next steps? Organizations will need to assess the environment to discover potential risks, including: 1.) financial risk: also, known as currency risk. The COVID-19 pandemic increased the exchanged rate volatility and stabilized after government intervention (Feng, Yang, Gong, \& Change, 2021), 2.) political risk: also, known as country risk. The risk can impact businesses based on governments unable to meet the social concerns of the people, including food shortage, job loss, unemployment, fear, and medical supplies can create challenges (Burns, 2020), and 3) commercial risk: this risk can impact both domestic and international organizations. For example, construction companies have been impacted by increase in product/services, higher labor-cost, extended project increase performance costs, and higher interest payments (Gilge, C, 2020). Some of these risks may be anticipated and managed with effective strategies to reduce their effects. However, they cannot be avoidable (Dunn, 2015; Stamouli \& Bouras, 2015). Leaders will need to develop and implement a plan of action prioritizing the actions that will minimize risks/challenges, add value to the organization, and develop resiliency for the future (PWC, 2021). 
For this paper, we will evaluate and analyze the application of adaptive leadership, adaptive challenges, and solutions during the post COVID-19 Pandemic. The adaptive challenges that impact employees and the organization, including culture, employee mental health/safety, job satisfaction, engagement, and employee morale. The following topics will be discussed, including: (1) COVID 19 overview, (2) challenges in the current business environment, (3) leadership defined, (4) adaptive challenge versus technical challenge (5) adaptive leadership approach and (6) and conclusion.

\section{COVID 19 OVERVIEW}

In 2019, a virus called severe acute respiratory syndrome coronavirus 2 (SARS-CoV-2) created a global Pandemic that has impacted people, businesses, economy, and government. The dangerous virus is known as COIVD-19. Currently, more than 235, 242,311 cases have been reported worldwide and 44,447, 518 cases in the United States. The number of deaths reported have been 4,808,608 and 719,037 in the United States (CDC, 2021; World meter, 2021). The next section will provide a brief overview on major corporations, small business, economy, and unemployment.

\section{Corporations}

As this Pandemic has spread across the global economy, 32 major companies have filed for bankruptcy or closed their doors due to COVID-19, including J. Drew, Hertz Global Branding, Whiting Petroleum Corporation, Chesapeake Energy Corporation, Stein Mart, Lord \& Taylor, Virgin Atlantic, California Pizza Kitchen, Tailored Brands (Men's Wearhouse), Golds Gym Neiman Marcus, JC Penny, GNC (Clifford \& Wahba, 2021; Moon, 2021; Reeth, 2021). According to S\&P Market Intelligence (2021), U.S. company bankruptcies have reached the worst level in 10 years with 630 filings in 2020 and 900 in 2021 . Out of the 630,155 companies have filed with assets greater than $\$ 100$ million in 2020 compared to 43 companies in 2021. Based on the findings, $48 \%$ of bankruptcies are mining, oil, and gas companies and retail trade companies. The largest bankruptcy filing in 2020 was Hertz Corporation with $\$ 25$ billion in assets. On a positive note, $88 \%$ decline in total assets in bankruptcies in 2021 compared to 2020, including Seadrill Limited (Mining, Oil, and Gas) with $\$ 7$ billion in assets (Corner Stone Research, 2021).

\section{Small Businesses}

Small Businesses have been impacted by COVID-19. As of April 2021, 34\% of small businesses are still closed, i.e., San Francisco has 48\% closure rate (Ghosh, 2021). Based on a survey by Yelp in 2020, 63,735 businesses have indicated that they have closed. In 2021, permanent closures have reached 97,966, representing $60 \%$ of closed businesses that won't be reopening (Sundaram, 2020).

\section{Economy}

Based on a USC study, USC Center for Risk and Economic Analysis of Terrorism Events (CREATE) have found the COVID-19 pandemic could result in net losses starting at $\$ 3.2$ trillion and reaching as much as $\$ 4.8$ trillion in U.S. real gross domestic product over the next two years. Based on the findings, researchers also project workforce decline in response to COVID-19. Some of the highlights are 54 million to 367 million workdays would be lost due to people getting sick with COVID-19, 2 million to nearly 15 million workdays would be lost due to employees staying home to care for sick loved ones, and Job losses could range from $14.7 \%$ to $23.8 \%$ and, in a worst-case scenario, affect an estimated 36.5 million workers (Gersema, 2020).

\section{Unemployment}

The National Bureau of Economic Research (NBER) explains the rise in unemployment was caused by the economic downturn resulting in an unprecedented loss of 22.1 million jobs between January 2020 and April 2020 compared to 9M in August 2021 (BLS, 2021; Congressional Research Service, 2020). Many individuals left the labor force over this period, and by April 2020 the labor force participation rate declined to $60.2 \%$, a level not seen since the early 1970 s. Job losses could range from $14.7 \%$ to $23.8 \%$ and, in a 
worst-case scenario, effect an estimated 36.5 million workers. This decline in the U.S. labor market corresponded with various governmental suggested or mandated stay at home orders in response to the COVID-19 pandemic and other related factors affecting U.S. demand (CRS, 2021). According to a survey of 3,700 adults conducted in April 2021, asked about their emergency savings. Based on the findings, 40\% of people with emergency savings prior to March 2020 have used half or more of the savings to cover living expenses (Rawan, 2021).

Based on the CARES Act, billions of dollars have been allocated towards small businesses to get back to some normalcy. Data from the Job Openings and Labor Turnover Survey (JOLTS) administered by BLS also point to a recovery in labor market conditions. Three procyclical metrics11 tracked by the JOLTS job openings, hires, and quits are at some of their highest levels since BLS began tracking these data in 2000. In June 2021, JOLTS reported that job openings were at 10.1 million, hires were at 6.7 million, and the number of quits was at 3.9 million, whereas in April 2020 job openings were at 5.4 million, hires were at 3.9 million, and the number of quits was at 2.1 million (BLS, 2021).

\section{IMPACT ON ORGANIZATIONS}

Today, during the COVID-19 Pandemic recovery phase, Leaders have been faced with many challenges during these times of uncertainty. Leaders have learned from the impact of COVID-19 the importance to identify the challenges, mobilize the teams, motivate employees, reevaluate jobs to meet the needs of followers, reassess strategies, and focus the attention of others getting back to work. This will require organizations to reevaluate business strategies, change old models, reintroduce new models, and adapt to the new norms of doing business in competitive marketplace. Reinventing the wheel may be the only solution for regaining customers, increasing revenue growth, and survive in a post-pandemic era (Deloitte, 2021). Below are key areas that have impacted organizations, include:

\section{Customers}

The COVID-19 pandemic has driven companies to reconsider how to deliver products/services to customers, how to evaluate the customer experiences, how to engage a virtual work environment, and how digital technology can be used to support business continuity through the crisis and the future. With these emerging new behaviors, organizations have an opportunity to expand existing offerings and creating new lines of service which will capture new marketplace opportunities and digital customer segments. For some retailers, implementing a delivery service that minimizes human contact, includes curb-side and pick-up services for customers (Accenture, 2020).

\section{Workforce}

Many organizations are experiencing workforce disruption that are impacting work culture, roles and responsibilities, and the future. How will organizations use technology, engagement programs, and data to increase employee engagement, productivity, and collaboration? Essentially, all organizations are evaluating short-term and long-term strategies that can be implemented to promote a productive and engaging virtual workforce environment while supporting the employees struggles to cope with anxiety, stress, and other aspects impacting their daily lives (Deloitte, 2021). Many organizations are now adapting the work strategies to a virtual work environment as the new "norm."

\section{Supply Chains}

Many organizations have had to rethink how will they rebuild their supply chains and meet the consumer demand for products. Some of the challenges with COVID-10, have impacted consumer buying behaviors, supply chains, and getting products to market. As organizations are responding to the pandemic, leaders need to prioritize the implementation of agile ways to improve the value chain transformation during times of uncertainty (Deloitte, 2021). 


\section{Global Business Outlook}

Financial markets, government agencies, and businesses are assessing the impact COVID-19 with have on the US and Global economy. According to Accenture (2020), organizations need to anticipate the potential short and long-term effects. Therefore, leaders need to react quickly to optimize their organizations strengths by rebalancing the level of risk and cashflow, while assessing the environment for growth opportunities during the pandemic. Based on the liquidity challenges, leaders will need to address and implement strategies to reduce costs, improve profitability, and use funding to invest in new growth opportunities. Other strategies many include closing businesses, add new products/services, and/ or implement diversification strategies. Many organizations are confronted with a significant decrease in sales, revenue, and increased costs. Implementation of new strategies will need to adapt to the changing global market may require investments in new processes, key technologies, processes, and human capital. For some organizations survival may require liquidity or closure of sites to stay afloat (Accenture, 2020; Deloitte, 2021).

\section{Industries}

COVID-19 has impacted all industries with varying degrees of severity. Some industries have implemented strategies to provide some protection during the crisis, while other industries continue to struggle with the new "normal." Based on status of doing business, global supply chains are disrupted and unable to deliver products/services on time, consumer demand patterns are shifting due to lockdowns, and the government, markets, and different regions are responding with different tactics to the COVID-19 crisis (Deloitte, 2021). The next section will discuss the challenges related to the COVID-19 pandemic

\section{ORGANIZATIONAL CHALLENGES IN COVID-19}

Today, organizations have transformed from the simplified defined functions to organizations focused on formalized processes, specialized products/services, increased vertical spans of control/hierarchy, complex matrices, multiple departments, and centralized decision making as the norm of global companies in the current landscape (Conger, Spreitzer, \& Lawler, 1999; Peng, Lu, \& Peters, 2014).

Due to these changes, organizations are faced with a complexity of challenges, including globalizations, intense competition, sustainability, speed and responsiveness to environmental changes, and the digital revolution (Daft, 2021). As a result of these changes, organizations to develop strategies that will adapt to marketplace that impact the organizations success (IBM, 2021). According to an IBM report (2021), the five key insights from leading executives for the post-pandemic business landscape, would be to increase digital transformation opportunities, the future of a diverse work force, transparency across the organization, and environmental and employee health sustainability. Together, they provide a playbook for proactive leaders who understand the world is changing more rapidly than before COVID- 19 .

Organizations are also dealing with a unique set of workforce challenges that are focused on the organizational work environment, customer's safety, mental health, critical roles, and flexible work schedule (PWC, 2021). In a recent SHRM survey of 1,099 employees, more than $40 \%$ of employees are burned out, exhausted, and feel hopeless. Based on the findings, 37\% who are unable or cannot telecommunicate are concerned about their pay and benefits compared to $22 \%$ of employees who are able to telecommunicate full-time. Another finding shows 55\% of employees are experiencing less interest and satisfaction in doing their job and less committed and loyal to the organization due to the stress of working remotely (Smith, 2021).

For organizations, all these challenges will require leaders that influence and motivate customers in a changing work environment that promotes a productive and aspiring culture (SHRM, 2021). As organizations shy away from the pre-COVID-19 normal practices, they are implementing different approaches in organizing and managing their people, operations, and effectively sustain a competitive advantage in a COVID-19 environment. Some of the tech companies like Apple, Google, Facebook, and Microsoft have developed work remote approaches to adapt to today's COVID-19 environmental demands (Ortutay, 2021). 


\section{LEADERSHIP DEFINED}

Leadership research has demonstrated that there are as many definitions for leadership as the people that have tried to define it (Stogdill, 1974; Rost, 1991). Over the century, the evolution of leadership definitions has been influenced by many factors, including behaviors, personality, influence, followers, situations (i.e., world events), and communication process. According to Northouse (2019), leadership has been conceptualized based on the following components, including (1) leadership is a process: transaction event between leader and follower, (2) leadership requires influence: leaders affect and communication process between leaders and followers Ruben \& Gigliotti, 2017), (3) leadership requires individuals and groups: leaders influence a group of individuals, and (4) leadership requires common goals: leaders and followers have a common purpose. Based on the components, Northouse states the definition of leadership "is a process whereby an individual (leader) influences a group of individuals to achieve a common goal" (2019).

For leaders in a post COVID-19 Pandemic, they will need develop different skill, behaviors, and competencies than leaders in the past. According to Cote (2012), Kets de Vries is one the world's foremost thinker on leadership, explains a leaderships power of position, status, and level of seniority is less important than your ability to implement change during times of uncertainty. You have to anticipate what lies ahead, recognize discontinuities" and anticipate the meaning of those discontinuities in your environment (Kets de Vries, 2005). As leaders are being evaluated by organizations during times of change and uncertainty, leaders that encompass key traits, skills, and behaviors have the ability create a sense of urgency that motivates, inspires, and empowers others (Kotter, 1988; Kotter, 1990; Kotter, 2012). The next sections will discuss technical and adaptive challenges, differences between technical and adaptive challenges, adaptive leadership, six behaviors of adaptive leadership, and impact on followers.

\section{WHAT ARE THE DIFFERENCES BETWEEN TECHNICAL VERSUS ADAPTIVE CHALLENGES?}

In this section, technical and adaptive challenges will be identified, the difference between the two challenges will be explored, and examples applied for each challenge. During the post COVID-19 Pandemic recovery phase, leaders may not be familiar with adaptive challenges and technical challenges. Why is this important for leaders to differentiate between the two challenges? For a leader to implement a solution for an adaptive challenge as a technical challenge, would be detrimental to the organization. This would be a big mistake. Not to mention, the challenge would not be resolved.

\section{Technical Challenges}

Technical challenges in organizations are issues/problems that are clearly defined, the solution is known, and can be solved by experts with known skills or training. For technical challenges, people rely on the leader for a solution, and they accept the leader's authority to solve the problem. Factors to consider:

- Easy to identify - clearly defined, i.e., virtual meeting versus face-to-face meeting with Zoom, Microsoft Team, etc...

- Minimal effort to resolve by an expert or authority, i.e., IT Department implements technical solution for new monitor.

- Organizational change minimal - impact one location, i.e., implementation of new computer in the office.

- People are more apt to accept technical solutions, i.e., IT Help Desk resolves email issue.

\section{Adaptive Challenges}

Adaptive Challenges are different, because they are not clearly defined or easy to identify, they require learning to understand what is going on, and the solutions require learning to develop new tools, methodologies, and practices. The challenges cannot be solved by expertise or authority. Leaders encourage 
followers to define issues/problems that are not easy to solve or resistant to change, identity solutions for the challenging issues/problems. Due to the complexity of the issues/problems, will require followers to change their beliefs, values, and (Northouse, 2019). Factors to consider:

- Adaptive challenges are difficult to identify, unpredictable, complex, and ambiguous

- Solutions will require people to change their beliefs, values, perceptions, behaviors, and attitudes

- Stakeholders need to be the people working on it

- Implementing change involves levels, including individuals, teams, and organization.

- People are not apt to accept change, i.e., requires buy-in.

- The solution will require learning, longer process, and experimentation with new strategies, technologies, and methodologies. Timeline difficult to ascertain!

For adaptive challenges, a COVID-19 example could be a leader reorganizing department in company resulting in either reduction/consolidation of departments, layoffs, and increased responsibilities for others. The CEO demotes or fires the leader for lack of implementation of the reorganization. What are the key elements? Employee are accepting the new leader and shifting their loyalties from the old leader to the new leader. The leader is providing the support to help the employee better understand the reasons for the previous failed reorganization. Leader motivates, inspires, and empowers the employees despite the reduction/consolidation of departments. Leader able to increase employee job satisfaction and productivity during a time of uncertainty and disruption.

\section{If You Are Having a Difficult Time Distinguishing the Adaptive Challenges Versus Technical Challenges? Ask Your People Five Questions (O’Malley \& Cebula, 2015)}

1. When you think about the future of your organization dealing with post-COVID-19 pandemic, what concerns you the most?

2. What makes progress difficult on this concern? Process Do you have challenges (issues or barriers) among team members or organization hinder the progress on this concern.

3. How adaptive leadership will help us to overcome those barriers?

4. that will make adaptive leadership difficult for you? Identifying adaptive challenges won't be easy and require time to find solutions.

5. What will it take to build adaptive leadership within your group?

For adaptive leadership, it is a complex process that involves several components, including identifying technical and adaptive, implement key leadership behaviors, encourage productive adaptive work, and help followers find solutions to their challenging issues/problems. In the next section, the technical and adaptive challenges were identified. The next section will define adaptive leadership and explore the applications of the six leadership behaviors in an adaptive work environment.

\section{ADAPTIVE LEADERSHIP}

Adaptive leadership was developed on the data that defines it as a process that can be complicated, ambiguous, messy, chaotic, and considered complex with no easy solutions. For leaders to transform change, specific behaviors will be necessary in this process for followers and organizations during times of uncertainty and change (Cote, 2012; Heifetz \& Laurie, 2001).

Adaptive leadership explained is not a formal process that may require personal traits, authority, and power to be effective (Cote, 2012; Heifetz \& Laurie, 2001). Heifetz, Kania, and Kramer (2004) explain adaptive leadership is a process that includes the following steps: (1) identify the problem as a technical problem that is well defined, answer is known, implementation process is specific, and solution can be resolved by organization or technical expertise. If the problem is an adaptive challenge, they are complex, the solution will require learning with new technologies, strategies, and methodologies, longer process, and timeline is difficult to ascertain, (2) focus attention by including stakeholders in identifying the problem and working together in a collective manner that will require changing their mindset in the way they have 
worked together in finding solutions, since the problem is rooted in their attitudes, priorities, and behaviors, (3) frame the issue and manage conflict by mobilizing stakeholders to achieve positive change in a nonthreatening environment by encouraging creative thinking, debate, and other methods focused on solutions for change (Cote, 2012; Heifetz et al., 2004).

\section{Adaptive Leadership Approach in Adaptive Work Environment}

In this approach, adaptive leadership is concerned with the behaviors of the leader that engage in activities that mobilize, motivate, organize, orient, and focus on the attention of the followers. Adaptive leadership encourage others to learn new ways to address and resolve changes that impact their lives (Cote, 2012; Heifetz, Grashow, \& Linsky, 2009: Heifetz et al. 2004). Due to the many challenges in society, leaders are met with adaptive challenges that will encourage participation with followers to find solutions, including work culture, job satisfaction, employee engagement, leadership changes, and employee mental health. For adaptive leaders, it is important to provide support followers to identify their issues/problems and help find solutions during times of change, may include: (1) leaders gets on the balcony to see the "big picture", (2) leader helps followers identify the adaptive challenge, (3) leaders regulate distress by monitoring the levels of productive stress, (4) leaders maintain disciplined attention, (5) leaders give the work back to the followers, and (6) leaders ensure that voices from below will be heard (Cote, 2012; Heifetz \& Laurie, 2001; Heifetz \& Laurie, 1999).

\section{Leadership Behaviors}

The first leadership behavior is "Get on the Balcony" is a required before using the other five leadership behaviors. Adaptive leaders will view the business from the balcony and get the "big picture" perspective. This will enable them to view patterns, trends, and potential challenges in the situation. The benefit of leaders viewing from the balcony allows them to see day-to-day operations, communicate valuable information to the executive management team, and allow for the utilization of organization resources to change in the present and shape the future (Cote, 2012; Heifetz \& Laurie, 2001). This is an important step for leaders to assess the COVID-19 current landscape, opportunities, threats, and challenges that are impacting their business. Heifetz and Laurie (2001) states "one has to get accustomed to getting on the balcony, delaying the impulse, and asking, what is this guy really talking about? Is there something we're missing?"

The second leadership behavior, "Identify the Adaptive Challenge" requires leaders to distinguish between technical problems from adaptive challenges. Technical problems can be identified, solutions can be solved by experts with adequate resources and training. For adaptive challenges, they are not easily identified, challenges can be ambiguous, complex, and unpredictable, and finding solutions require commitment from the key stakeholders. In times of stress, leaders may be pressured to make quick decisions (i.e., knee-jerk reaction) resulting in setbacks to the organization when treating technical problems as adaptive challenges and vice versa. For adaptive leaders, the solution to the problem lies within the followers of the organization. The challenges may include employee stress, lack of motivation, lack of engagement and job satisfaction, and factors impacting the overall organizational culture (Cote, 2012; Heifetz et al., 2004; Heifetz \& Laurie, 2001; Heifetz \& Laurie, 1999).

The third leadership behavior, "Regulate Distress" the leader will need to be aware of stress level with followers. Adaptive leaders will need to produce moderate stress to facilitate the need for change. During the change process, this may create distress and uncertainty with followers. When followers are learning new responsibilities and processes, they tend to be stressed when finding a solution for their issue or concern. This can be counterproductive and devasting in progress. Therefore, leaders will need to get buyin, stress sense of urgency, and provide direction with followers to understand the need for change. To ensure followers stress is in a productive range, the leader will monitor and regulate stress (Cote, 2012; Heifetz \& Laurie, 1999).

Based on adaptive leadership, it can be considered a balancing act for leaders when working with overwhelmed followers while empowering change (Cote, 2012; Heifetz \& Laurie, 2001; Heifetz \& Laurie, 1999). The challenge for leaders is to help others recognize the need for change. This means the leader 
needs to monitor and regulate stress to ensure it is in a productive range. For the leader to maintain productive levels of stress, three fundamentals can be followed by leaders (Cote, 2012; Heifetz \& Laurie, 2001), including:

1. leader creates a holding environment allowing people the opportunity to discuss the challenges, construct of the issue, analyze the assumptions impacting values and perspectives, and communicate with followers the how and why they will need to change.

2. a leader is responsible for adaptive work leadership responsibilities including providing direction, protection, orientation, conflict management, and productive norms.

3. a leader needs to maintain composure and balance in the process of finding equilibrium during distressful and uncertain times.

For this leadership behavior, the leader will nudge followers out of their comfort zones. This will create stress resulting in disequilibrium during times of change and uncertainty. Moderate levels of stress are common during the adaptive work process. This will help followers and the organization maintain a productive level of stress that promotes change and growth (Cote, 2012). Adaptive leaders will maintain productive levels of stress with followers, using the following process: (1) providing direction: involves identifying the adaptive challenges, provide followers a sense of clarity, and reducing the stress in times of uncertainty (2) provide protection: the leader will monitor the level of change and stress among followers, (3) orientation: the leader will orient followers to new roles and responsibilities during the adaptive change (4) conflict management: the leader will manage conflicts among followers and offer the opportunity to learn and grow, and (6) productive norms: the adaptive leader will establish the norms of behaviors within the organization considered productive and reinforce positive influence on the groups progress (Cote, 2012; Heifetz \& Laurie, 2001).

The fourth leadership behavior, "Maintain Disciplined Attention" requires leaders to encourage followers to focus on the adaptive work that needs to be completed. It is imperative that adaptive leaders maintain a disciplined attention to ensure followers understand the need for change. Leaders need to emphasize change that may require followers to change their beliefs, values, and behaviors. It is common for people to resist change because they strive for a balance in their lives instead of disequilibrium in our daily lives. Adaptive leaders need to be aware of avoidance behaviors that may be hindering change in the organization. (Cote, 2012; Heifetz \& Laurie, 2001; Heifetz \& Laurie, 1999). For followers engaging in avoidance behaviors, adaptive leaders will need to encourage and mobilize people to focus on confronting their problems and focus on the work that needs to be done (Cote, 2012; Heifetz \& Laurie, 1999; Heifetz $\&$ Laurie, 2001). For organizations to succeed in change, the leaders and followers will need to engage in a collective team effort to solve adaptive challenges (Cote, 2012; Heifetz \& Laurie, 2001).

The fifth leadership behavior, "Give the Work Back to People" leaders will provide some direction and structure while minimal leadership influence and authority. For leaders, this requires developing and instilling self-confidence instead of a dependent relationship with followers. Through a supportive role, leaders can change behaviors while reducing complacency and work avoidance that distract followers from dealing with adaptive issues (Cote, 2012; Heifetz \& Laurie, 2001; Heifetz \& Laurie, 1999). To accomplish adaptive work, leaders need to trust their followers by giving them back the work. This will require developing a collective self- confidence, encourage risk taking, and increased responsibilities for the success of the organization achieving adaptation (Cote, 2012; Heifetz \& Laurie, 2001; Heifetz \& Laurie, 1999).

The sixth leadership behavior "Protect Voices of Leadership from Below" focuses on followers, that part of the majority in-group members of the organization. Leaders need to resist the tendency to shut down or minimize their voices being heard. Many of the out-group individuals consider their information ineffective and may be considered a challenge and construed as disruptive to the "normal" way of doing business. These outliers are usually considered a threat because they provoke rethinking that impact the equilibrium of the organization. Instead of being taken seriously, these followers are neutralized and silenced before their creative perspectives are heard. Most of these followers, lack the confidence and passion to speak out and share the wealth of information that may be of value. Instead, they choose the wrong channels of command, pick the wrong place, timing is bad, or disregards the appropriate lines of 
communication (Cote, 2012; Heifetz \& Laurie, 2001; Heifetz \& Laurie, 1999). Adaptive leaders need to resist the tendency to minimize the voices of the majority. Instead, leaders need to take control and allow the voices from below that may have questions for identifying adaptive challenges and provide protection when contractions are raised on internal weaknesses (Cote, 2012; Heifetz \& Laurie, 2001; Heifetz \& Laurie, 1999).

As organizations evaluate leadership during the post COVID-19 Pandemic, the adaptive leadership approach is a process focused on the followers and organization during these times of change, including evaluating values, behaviors, and actions to help others address and understand their concerns affecting their lives and the organization (Cote, 2012; Northouse, 2007; Northouse, 2016; Northouse, 2019).

\section{CONCLUSION}

The COVID-19 Pandemic started in 2019 and continues through 2021 due to a virus called severe acute respiratory syndrome coronavirus 2 (SARS-CoV-2) with more than 235, 242,311 cases worldwide, 44,447,518 cases in the United States, and 4,808,608 deaths reported worldwide (CDC, 2021; World meter, 2021). More than 97,966 small businesses have closed, and several major corporations have filed for bankruptcy, including Hertz Global Branding, Chesapeake Energy Corporation, Stein Mart, Lord \& Taylor, Virgin Atlantic, California Pizza Kitchen, Tailored Brands (Men's Wearhouse), Golds Gym Neiman Marcus, JC Penny, GNC (Clifford \& Wahba, 2021; Reeth, 2021; Sundaram, 2020). Not to mention, COVID-19 pandemic could result in net losses starting at $\$ 3.2$ trillion and reaching as much as $\$ 4.8$ trillion in U.S. real gross domestic product over the next two years (Gerseman, 2020).

COVID-19 has influenced organizations to scan and evaluate the external environment to assess opportunities and threats, including global competition, changing markets, mergers and acquisitions, and other external factors. Some of these external factors have impacted organizations, how will affect how customers purchase goods and services? How will the workforce mentally adapt to a virtual work environment? How will organizations supply chain meet the demands of customers? Are CEO's able to assess the consequences of the marketplace on sales and profits? And are industries able to adapt to the "new" normal business operations? (Deloitte, 2012). COVID-19 has organization workforce challenges focused on the work environment, customer's safety, mental health, critical roles, and flexible work schedule (PWC, 2021). In a recent survey, more than $40 \%$ of employees are burned out, exhausted, and feel hopeless. Another finding shows 55\% of employees are experiencing little interest or pleasure in doing their job (Smith, 2021).

COVID-19 pandemic has created several challenges in organizations ranging from technical challenges and adaptive challenges. As organizations assess and evaluate the challenges, they are over-inundated with finding solutions in this ever-changing global marketplace. For technical challenges, they are well defined, simple, answers are known, and solutions can be resolved by the technical expertise and resources, i.e., organizations transferring to a virtual work environment require technical experts (Heifetz et al., 2004). For adaptive challenges, they are complex, ambiguous, unpredictable, answers are unknown, and the solution will require learning, longer process, and experimentation with new strategies, technologies, and methodologies (Northouse, 2019). Timeline difficult to ascertain. The solution process require input from the key stakeholders in the organization (Heifetz et al., 2004). For organizations to be successful, leaders will need to help followers identify key challenges, frame the issues with appropriate questions, and empower followers in the organization to find solutions (Northouse, 2019).

In the adaptive leadership approach, leaders work with followers to help them identify the adaptive challenges (i.e., issues, problems, and concerns) and find solutions. The key six leadership behaviors that are instrument in the process are get on the balcony (big picture), identify the adaptive challenge, regulating distress (monitor level of stress), maintain disciplined attention (focus on work), give the work back to the followers, and protect leadership voices from below (Northouse, 2019; Heifetz et al., 2004). Overall, adaptive leadership is effective when the leader engages in the leadership behaviors to help followers and organizations in providing solutions to adaptive challenges. 


\section{REFERENCES}

Accenture. (2020). COVID-19: New habits are here to stay for retail consumers. Retrieved from https://www.accenture.com/us-en/insights/retail/coronavirus-consumer-habits

Accenture. (2020). COVID-19: rebalance for resilience with M\&A. Retrieved from https://www.accenture.com/us-en/insights/strategy/coronavirus-mergers-acquisitions-resilience

Bureau of Labor Statistics (BLS). (2021). Labor force statistics from the current population survey. Retrieved from https://www.bls.gov/cps/effects-of-the-coronavirus-covid-19-pandemic.htm

Bureau of Labor Statistics (BLS). (2021). Ted: The economic daily. Retrieved from https://www.bls.gov/opub/ted/2021/unemployment-rate-drops-to-5-2-percent-in-august-2021.htm

Burns, L. (2020). 4 potential risks arising from COVID-19. Retrieved from https://www.willistowerswatson.com/en-US/Insights/2020/04/four-potential-political-risksarising-from-covid-19

Centers for Disease Control and Prevention (CDC). (2021). COVID-19 basics. Retrieved from https://www.cdc.gov/coronavirus/2019-ncov/your-health/about-covid-19/basics-covid-19.html

Clifford, L., \& Wahba, P. (2021). A running list of companies that have filed for bankruptcy during the coronavirus pandemic. Retrieved from https://www.yahoo.com/now/running-list-companiesfiled-bankruptcy-110000155.html

Conger, J.A., Spreitzer, G.M., \& Lawler, E.E., III. (Eds.). (1999). The leader's change handbook: An essential guide to setting direction and taking action. San Francisco, CA: Jossey-Bass.

Congressional Research Service (CRS). (2021). Unemployment rates during the COVID-19 pandemic. Retrieved from https://sgp.fas.org/crs/misc/R46554.pdf

Cornerstone Research. (2021). Trends in large corporate bankruptcy and financial distress. Retrieved from https://www.cornerstone.com/Publications/Reports/Trends-in-Large-Corporate-Bankruptcyand-Financial-Distress-Midyear-2021-Update

Cote, R. (2012). Comprehensive examination. Unpublished paper. Capella University.

Daft, R. (2021). Organization theory and design (13th ed.). Boston (Mass.): Cengage Learning.

Deloitte. (2021). US business impact of COVID-19: reopen and recover with confidence. Retrieved from https://www2.deloitte.com/us/en/pages/about-deloitte/articles/business-impact-us-covid-19.html

Dunn, J. (2015). No country for young people. Maclean's, pp. 34-35.

Feng, G., Yang, C., Gong, Q., \& Change, C. (2021). What is the exchange rate volatility? Response to COVID-19 and government interventions? Economic Analysis and Policy, 69, 705-719. https://doi.org/10.1016/j.eap.2021.01.018

Geresma, E. (2020). Business closures and partial reopening's due to COVID-19 could cost the U.S. trillions. Retrieved from https://news.usc.edu/178979/business-closures-covid-19-pandemicunited-states-gdp-losses/

Ghosh, I. (2021). 34\% of America's small businesses are still closed due to COVID-19. Here's why it matters. Retrieved from https://www.weforum.org/agenda/2021/05/america-united-states-covidsmall-businesses-economics/

Gilge, C. (2020). COVID-19 risks for construction owners. Retrieved from https://advisory.kpmg.us/articles/2020/covid-19-risks-for-construction.html

Heifetz, R., \& Laurie, D. (2001). The work of leadership. Harvard Business Review, 79(11), 131-141. Retrieved from Business Source Complete database.

Heifetz, R., Grashow, A., \& Linsky, M. (2009). Leadership in a (Permanent) Crisis. Harvard Business Review, 87(62-9), 153. DOI: 10.1037/e563252009-001

Heifetz, R., Kania, J., \& Kramer. (2004). Leading boldly. Stanford Social Innovation Review, 2(3), 20 31. Retrieved from ABI/INFORM Global. (Document ID: 776348921).

Kets de Vries, M. (2005). Global executive leadership inventory: Participant workbook. Retrieved from http://www.gelionline.com/geli/ 
Koufteros, X., Peng, X., Lu, G., \& Peters, R. (2014). The Impact of Organizational Structure on Internal and External Integration: An empirical, cross-regional assessment. Journal of Organization Design, 3(2), 1-17. https://doi.org/10.7146/jod.7386

Moon, B. (2021). 32 bankruptcy filings chalked up to COVID-19. Kiplinger. Retrieved from https://www.kiplinger.com/investing/603194/bankruptcy-filings-chalked-up-to-covid-19-2021

O’Malley, E., \& Cebula, A. (2015). Your leadership edge. Wichita, KS: KLC Press.

Otutay, B. (2020). Working from home post-COVID-19? Facebook, Apple, Twitter and Microsoft embracing remote work. USA Today. Retrieved from https://www.usatoday.com/story/tech/2020/05/22/coronavirus-remote-work-postpandemic/5242420002/

PWC. (2021). Accessing the review. Retrieved from https://www.pwc.com/gx/en/issues/crisissolutions/after-action-review.html

PWC. (2021). COVID-19 Workforce challenges \& tips: How to ensure business continuity amidst the challenges being faced due to COVID-19 outbreak. Retrieved from https://www.pwc.com/mt/en/publications/humanresources/covid-19-workforce-challenges/covid19-workforce-challenges-and-tips-business-continuity.html

Rawan, L. (2021). Forbes: Here's how the pandemic shattered the emergency savings rule of thumb. Retrieved from https://www.forbes.com/advisor/personal-finance/emergency-fund-survey/

Reeth, M. (2021). 7 companies that went bankrupt due to COVID-19. Retrieved from https://money.usnews.com/investing/stock-market-news/slideshows/covid-bankruptcompanies?slide $=10$

Rost, J. (1991). Leadership for the twenty-first century. New York, NY: Praeger.

Ruben, B., \& Gigliotti, R. (2017). Communications: sine qua non of organizational leadership theory and practice. International Journal of Business Communications, 54(1), 12-30.

S \& P Global. (2021). Market Intelligence: US corporate bankruptcies end 2020 at 10-year high amid COVID-19 pandemic. Retrieved from https://www.spglobal.com/marketintelligence/en/newsinsights/latest-news-headlines/us-corporate-bankruptcies-end-2020-at-10-year-high-amid-covid19-pandemic-61973656

SHRM. (2021). Toolkit: Developing organizational leaders. Retrieved from https://www.shrm.org/resourcesandtools/tools-andsamples/toolkits/pages/developingorganizationalleaders.aspx

Smith, A. (2021). SHRM: Ongoing pandemic takes toll on workers' mental health. Retrieved from https://www.shrm.org/resourcesandtools/legal-and-compliance/state-and-localupdates/pages/coronavirus-ongoing-pandemic-worker-mental-health.aspx

Stamouli, N., \& Bouras, S. (2015). Greek economy slipping back into recession, says analysts. Wall Street Journal, 1.

Stogdill, R. (1974). Handbook of leadership: a survey of theory and research. New York, NY: Free Press.

Sundaram, A. (2020). Yelp data shows $60 \%$ of business closures due to the coronavirus pandemic are now permanent. Retrieved from https://www.cnbc.com/2020/09/16/yelp-data-shows-60percentof-business-closures-due-to-the-coronavirus-pandemic-are-now-permanent.html

Worldometer. (2021). COVID-19 Coronavirus pandemic. Retrieved from https://www.accenture.com/usen/insights/retail/coronavirus-consumer-habits 